\title{
LIQUID-LIQUID PHASE SEPARATION BY NUCLEATION AND GROWTH IN SOLUTIONS OF POLY(2,6 DIMETHYL-1,4 PHENYLENE OXIDE) IN TOLUENE
}

\author{
P. T. VAN EMmeriK* and C. A. SMOLDERS \\ University of Technology Twente, Enschede, The Netherlands
}

(Received 11 January 1973)

\begin{abstract}
In solutions of poly(2,6 dimethyl-1,4 phenylene oxide) in toluene, the nucleation of the newly formed phase during liquid-liquid phase separation takes place after induction periods which vary between several minutes (at temperatures close to the spinodal) and several hours (at temperatures close to the cloudpoint). The growth of the nuclei in the initial stages is diffusion controlled. The diffusion coefficients and the activation energy of diffusion were calculated. From these values, together with the calculated volume free energies and the experimental induction times, an estimate could be made of the size of a critical nucleus and of the surface free energy of the nuclei.
\end{abstract}

\section{INTRODUCTION}

DIRECT measurements of homogeneous nucleation rates have been possible in inorganic glass-forming systems in which non-crystalline phase separation occurs below the liquidus. ${ }^{(1)}$ By electron microscopy, direct measurements could be performed of nucleation rates during transient times, as well as in the steady-state. The kinetics of these separations occurring within the miscibility gap were described in terms of an induction period, followed by nucleation and growth or by spinodal decomposition.

Phase separation phenomena of poly(2,6 dimethyl-1,4 phenylene oxide)-toluene solutions proceed along analogous ways. ${ }^{(2,3)}$ Upon cooling a homogeneous solution, liquid-liquid phase separation will take place either by the nucleation and growth mechanism or by the spinodal decomposition. Electron-microscopy has shown that nucleation takes place after induction periods which, depending upon temperature and concentration, can reach values up to several hours. ${ }^{(4)}$ In contrast with most other liquid polymer systems, the growth rates of the nuclei, once formed, have such relatively small values that the growth of the nuclei can be followed under the light microscope.

A survey of the observations of nucleation and growth of solutions of poly $(2,6$ dimethyl-1,4 phenylene oxide) in toluene is presented in this paper.

\section{EXPERIMENTAL}

Appropriate amounts of poly(2,6 dimethyl-1,4 phenylene oxide) and toluene were weighed into glass tubes with two parallel sides, the tubes being sealed at liquid nitrogen temperature under vacuum. Complete dissolution was obtained by heating in a thermostat bath at $150^{\circ}$. Subsequently these tubes were brought into an air thermostat at the temperature at which phase separation by nucleation and growth was known to occur. The temperature control was within $0.11^{\circ}$. The growth of the nuclei was studied under the light microscope with photographic means.

* Present address: General Electric Plastics B.V. Bergen op Zoom, The Netherlands. 


\section{Induction times}

\section{THEORETICAL CONSIDERATIONS}

The rate of formation of nuclei at a certain time $t$ after changing the stability conditions is given by $:^{(5,6)}$

$$
J(t)=J_{0} \exp (-\tau / t)
$$

$J(t)=$ number of nuclei formed per unit time at time $t$

$J_{0}=$ nucleation rate in the steady state

$\tau=$ induction time.

For the induction time, the following expression is valid $:^{(6,7)}$

$k=$ Boltzmann constant

$$
\tau=k T / 4 s\left(n^{*}\right) \nu \lambda
$$

$T=$ absolute temperature

$s\left(n^{*}\right)=$ surface of a critical nucleus that contains $n^{*}$ particles

$\nu=$ transport frequency

$$
\lambda=-\left[\frac{\mathrm{d}^{2} \Delta G(n)}{\mathrm{d} n^{2}}\right]_{n \approx n^{*}} .
$$

The free enthalpy of formation of a spherical nucleus that contains $n$ particles, $\Delta G(n)$, is given by: ${ }^{(7)}$

$$
\Delta G(n)=(36 \pi)^{1 / 3} n^{2 / 3} v^{2 / 3} \sigma-n k T \ln \beta
$$

$v \quad=$ volume of a molecule

$\sigma=$ interfacial free energy

$\beta=$ a measure of the supersaturation of the system.

From (3) one can derive that

$$
\lambda=\left(\frac{32 \pi}{81}\right)^{1 / 3} v^{2 / 3} \sigma n^{*-4 / 3}
$$

and

$$
n^{*}=\left(\frac{32 \pi}{3}\right) v^{2} \sigma^{3}(k T \ln \beta)^{-3}
$$

Substitution of (5) in (4) gives

$$
\lambda=(32 \pi)^{-1} v^{-2} \sigma^{-3}(k T \ln \beta)^{4} .
$$

For a condensed system, the supersaturation of the system is related to the volume free energy, controlling phase separation, by:

$$
\Delta G_{v}=\frac{k T \ln \beta}{v}
$$

The expression for $\lambda$ therefore can be written as

$$
\lambda=(32 \pi)^{-1} v^{+2} \sigma^{-3}\left(\Delta G_{v}\right)^{4} .
$$


The transport frequency $\nu$ for a liquid polymer system is related to the jump frequency ${ }^{(8,9)} F$ of the segments of the polymer.

For a volume unit of the polymer system one can write ${ }^{(10)}$

$$
\nu=N_{1} \delta F_{0} \exp \left(-\Delta G_{a} / k T\right)
$$

$N_{1}=$ number of molecules in a volume unit

$\delta=$ interparticle distance

$F_{0}=$ a factor proportional to $k T / h$ ( $h$ is Planck's constant) and dependent upon the stiffness of the polymer chain. ${ }^{(11)}$

$\Delta G_{a}=$ activation energy for diffusion.

Substitution of (8) and (9) in (2) results in:

$$
\tau=\frac{32 \pi k T \sigma^{3} \exp \left(\Delta G_{a} / k T\right)}{4 s\left(n^{*}\right) N_{1} \delta F_{0}\left(\Delta G_{v}\right)^{4} v^{2}}
$$

Since $s\left(n^{*}\right)$ can be expressed in terms of $r^{*}$, the size of the critical nucleus, and since this latter quantity is related to $\sigma$ and $\Delta G_{v}$ by

$$
r^{*}=\frac{2 \sigma}{\Delta G_{v}}
$$

Eqn. (10) can be written as:

$$
\tau=\frac{k T r^{*} \exp \left(\Delta G_{a} / k T\right)}{4 N_{1} \delta F_{0} \Delta G_{v} v^{2}}
$$

For our system $\tau$ can be obtained directly from experiments, $\Delta G_{v}$ can be calculated and $\Delta G_{a}$ can be obtained from experimental growth data of the nuclei. Therefore $r$ * can be calculated from Eqn. (12) if suitable values for $N_{1}, \delta, F_{0}$ and $v$ are inserted. This calculated value for $r^{*}$ will be compared with an experimental value obtained earlier by electron microscopy. ${ }^{(4)}$

Using Eqn. (11), $\sigma$ can be calculated also.

\section{Calculation of $\Delta G_{v}$}

The volume free energy, $\Delta G_{v}$, can be calculated if, for the system, the Gibbs free energy of mixing, $\Delta G_{m}$, is known as a function of concentration and temperature.

For a polymer solution, $\Delta G_{m}$, expressed in weight fractions, in a volume element, $\Delta V$, is given by: ${ }^{(12)}$

$$
\Delta G_{m} / R T=\left[w_{0} \ln w_{0}+\sum_{i} \frac{\mathrm{M}_{0}}{\mathrm{M}_{i}} w_{i} \ln w_{i}+g w_{0} w\right] \frac{\rho \cdot \Delta V}{\mathbf{M}_{0}} .
$$

$w_{0}=$ weight fraction of the solvent

$w_{i}=$ weight fraction of the polymer component $i$

$w=$ total weight fraction of the polymer

$\mathbf{M}_{0}=$ molecular weight of the solvent

$\mathrm{M}_{\mathbf{l}}=$ molecular weight of component $i$ of the polymer

$\rho=$ density of the solution

$R=$ universal gas constant

$g \quad=$ free enthalpy correction parameter. 
$\Delta G_{m}$ for the system poly(2,6 dimethyl-1,4 phenylene oxide) toluene can be calculated $^{(13)}$ with a temperature- and concentration-dependent interaction parameter $g$, given by

in which

$$
g=g_{0}+g_{1} w_{1}
$$

$$
g_{0}=\frac{566 \cdot 0-6 \cdot 7(T-273)}{R T}
$$

and

$$
g_{1}=\frac{1251 \cdot 8-0.7(T-273)}{R T}
$$

Taking $\rho \Delta V / \mathbf{M}_{0}=1$ in Eqn. (13), the free energies driving phase separation at various concentrations and temperatures can be obtained using the following expression:(1)

$$
\begin{aligned}
\Delta G_{v}= & \left\{\Delta G_{m}\left(w_{2}\right)-\Delta G_{m}\left(w_{1}\right)+\left(w_{3}-w_{2}\right) \mathrm{d} \Delta G_{m} / \mathrm{d} w_{2}\right. \\
& \left.-\left(w_{3}-w_{1}\right) \mathrm{d} \Delta G_{m} / \mathrm{d} w_{1}\right\} / V_{\mathbf{M}_{0}}
\end{aligned}
$$

where

$w_{2}=$ weight fraction of polymer in the homogeneous solution (i.e. before phase separation)

$w_{1}=$ weight fraction of polymer in the dilute phase at equilibrium

$w_{3}=$ weight fraction of polymer in the concentrated phase at equilibrium

$V_{\mathbf{M}_{0}}=$ volume of $\mathrm{M}_{0}$ of the homogeneous solution.

\section{Diffusion coefficient and activation energy of diffusion}

The diffusion coefficient for a particular process can be calculated if the rate of growth of a spherical particle can be measured and the degree of supersaturation is known. (14)

In systems where liquid-liquid phase separation is known to occur, the degree of supersaturation is expressed as:

$$
\frac{\Delta G_{v} \cdot v}{k T}=\ln \beta=f(S)
$$

Here $v$ again is the volume of a molecule (or polymer segment) and $f(S)$ is a complicated function of $S$, a measure of the supersaturation of the system. $S$ is equal to $r / D^{\frac{1}{t}} t^{\frac{1}{2}}$, where $r$ is the radius of the growing particle, $D$ is the diffusivity and $t$ is time. Frank ${ }^{(14)}$ has tabulated $f(S)$ over a wide range of values of $S$. Therefore, using Eqn. (18), $S$ can be obtained from Frank's tabulated values.

Since

$$
\mathrm{d} A / \mathrm{d} t=4 \pi D S^{2}
$$

in which $\mathrm{d} A / \mathrm{d} t$ represents the growth of area of a spherical particle, $D$ can be calculated.

From the plot of $\ln D$ vs $1 / T$, the activation energy of diffusion can thus be obtained. 


\section{Experimental $\tau$-values}

\section{RESULTS}

The growth of the nuclei has been measured at temperatures between the cloudpoint and the spinodal of solutions of 30,40 and 50 per cent of weight poly $(2,6$ dimethyl-1,4 phenylene oxide) in toluene.

The growth data of a 30 per cent of weight solution at various temperatures are shown in Fig. 1. For that particular solution, the cloudpoint $T_{\text {cip }}=60^{\circ} \mathrm{C}$ and the spinodal temperature $T_{\mathrm{s}} \approx 38^{\circ} \mathrm{C}$. For a full cloudpoint curve and spinodal curve see Ref. 2.

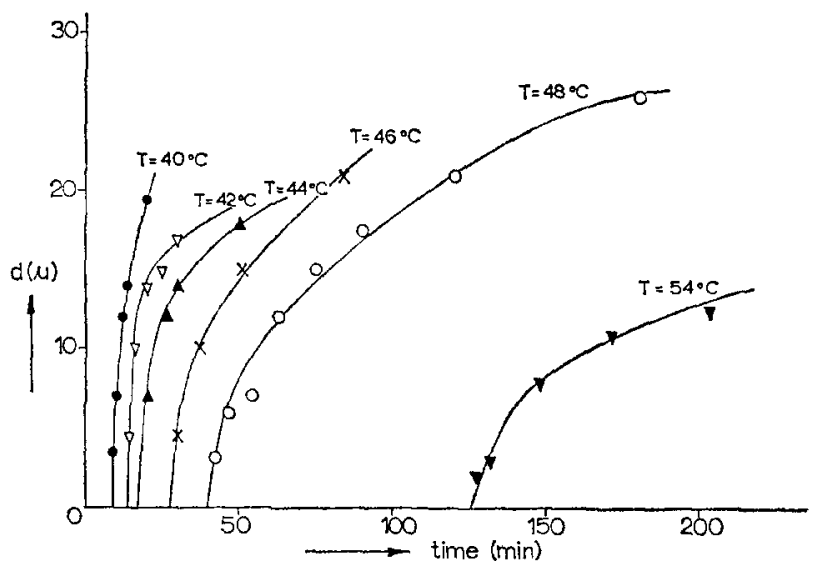

FIG. 1. Size of the nuclei vs time for a 30 per cent by weight poly(2,6 dimethyl-1,4 phenylene oxide)-toluene solution at various temperatures. $d=$ dia. of the particle.

Nuclei were observed after a certain induction time which approached zero at temperatures near the spinodal temperature and which were several hours at temperatures close to the cloudpoint.

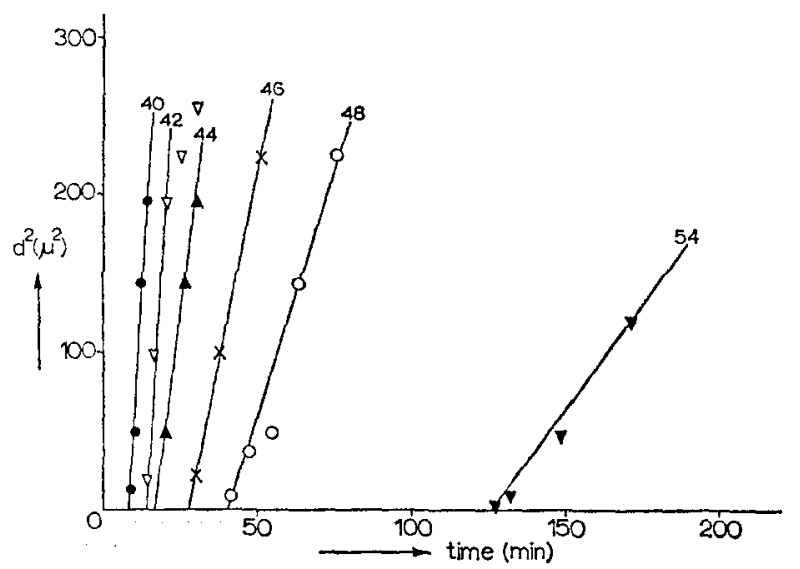

Fig. 2. Area of nuclei vs time for a 30 per cent by weight poly(2,6 dimethyl-1,4 phenylene oxide)-toluene solution at various temperatures; $d=$ dia. of the particle. 
To test the possibility that early in the induction period nuclei were formed and might be too small to detect under the light microscope, samples were studied at appropriate times and temperatures with the transmission electron microscope using the freeze etching technique during sample preparation. ${ }^{(4)}$ This investigation showed indeed that during the induction period no nuclei were formed.

By plotting $d^{2}$ vs $t$, as in Fig. 2, and extrapolating to $d^{2}=0$, the induction periods were obtained as a function of temperature (Table 1). The plot of $\ln \tau$ against $1 / T$ is linear (Fig. 3). This is rather unexpected, given the complicated dependency of $\tau$ on temperature suggested by Eqn. (12).

\begin{tabular}{|c|c|c|c|}
\hline$w$ & $\begin{array}{c}T \\
(\mathbf{K})\end{array}$ & $\stackrel{\tau}{\tau}$ & $\underset{\left(\mathrm{J} / \mathrm{cm}^{3}\right)}{\Delta G_{p}}$ \\
\hline 0.3 & $\begin{array}{l}313 \\
315 \\
317 \\
319 \\
321 \\
326 \\
327\end{array}$ & $\begin{array}{r}8 \\
14 \\
17 \\
27 \\
40 \\
100 \\
125\end{array}$ & $\begin{array}{l}3.51 \\
2.85 \\
2.22 \\
1.45 \\
1.27 \\
0.60 \\
0.57\end{array}$ \\
\hline 0.4 & $\begin{array}{l}328 \\
333 \\
335 \\
338\end{array}$ & $\begin{array}{r}4 \\
29 \\
43 \\
98\end{array}$ & $\begin{array}{l}1.73 \\
1.27 \\
1.00 \\
0.71\end{array}$ \\
\hline 0.5 & $\begin{array}{l}342 \\
345 \\
346 \\
348 \\
351\end{array}$ & $\begin{array}{r}5 \\
6 \\
13 \\
28 \\
51\end{array}$ & $\begin{array}{l}1.03 \\
0.99 \\
0.89 \\
0.71 \\
0.56\end{array}$ \\
\hline
\end{tabular}

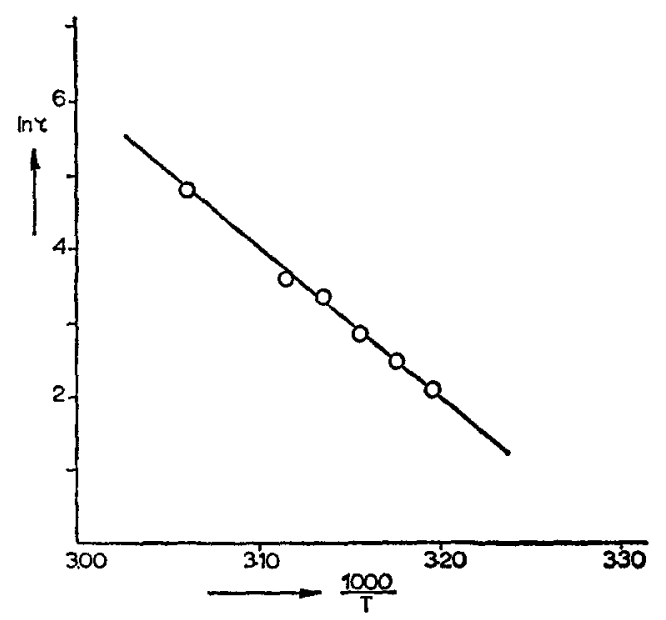

FIG. 3. The logarithm of the induction time vs $1 / T$ for a 30 per cent by weight poly(2,6 dimethyl-1,4 phenylene oxide)-toluene solution. 


\section{Calculation of $\Delta G_{v}$}

Using Eqn. (17), the volume free energy associated with phase separation for a 30,40 and 50 per cent of weight solution of poly(2,6 dimethyl-1,4 phenylene oxide) in toluene was calculated at various temperatures, while taking for $V_{\mathbf{M}_{\mathbf{0}}}$ the values $100 \cdot 10,98.06$ and 96.05 at the concentrations mentioned.

The results are given in Table 1.

Table 2. Calculated values of the diffusion coefficient and the activation energy of DIFFUSION OF POLY(2,6 DIMETHYL-1,4 PHENYLENE OXIDE)-TOLUENE SOLUTIONS

\begin{tabular}{|c|c|c|c|c|c|c|}
\hline$w$ & $\begin{array}{c}T \\
(\mathbf{K})\end{array}$ & $\underset{(\mathrm{S})}{f}$ & $S$ & $\begin{array}{c}\mathrm{d} A / \mathrm{d} t \times 10^{8} \\
\left(\mathrm{~cm}^{2} / \mathrm{min}\right)\end{array}$ & $\begin{array}{r}D \times 10^{9} \\
\left(\mathrm{~cm}^{2} / \mathrm{sec}\right)\end{array}$ & $\begin{array}{c}\Delta G_{a} \\
\text { (kcal/mol) }\end{array}$ \\
\hline $0 \cdot 3$ & $\begin{array}{l}313 \\
315 \\
317 \\
319 \\
321 \\
327\end{array}$ & $\begin{array}{l}0.143 \\
0.116 \\
0.089 \\
0.058 \\
0.051 \\
0.022\end{array}$ & $\begin{array}{l}0.73 \\
0.65 \\
0.55 \\
0.41 \\
0.37 \\
0.21\end{array}$ & $\begin{array}{r}82 \cdot 74 \\
75 \cdot 36 \\
54 \cdot 21 \\
31 \cdot 81 \\
24 \cdot 55 \\
8 \cdot 35\end{array}$ & $\begin{array}{l}2 \cdot 06 \\
2 \cdot 37 \\
2 \cdot 37 \\
2 \cdot 51 \\
2 \cdot 38 \\
2 \cdot 51\end{array}$ & $2 \cdot 07$ \\
\hline 0.4 & $\begin{array}{l}328 \\
333 \\
335 \\
338\end{array}$ & $\begin{array}{l}0.067 \\
0.049 \\
0.038 \\
0.027\end{array}$ & $\begin{array}{l}0.45 \\
0.37 \\
0.31 \\
0.25\end{array}$ & $\begin{array}{l}70 \cdot 60 \\
60 \cdot 01 \\
44 \cdot 10 \\
23 \cdot 99\end{array}$ & $\begin{array}{l}4 \cdot 63 \\
5 \cdot 82 \\
6 \cdot 08 \\
5.09\end{array}$ & 3.08 \\
\hline 0.5 & $\begin{array}{l}342 \\
345 \\
346 \\
348 \\
351\end{array}$ & $\begin{array}{l}0.039 \\
0.037 \\
0.033 \\
0.026 \\
0.020\end{array}$ & $\begin{array}{l}0 \cdot 31 \\
0 \cdot 30 \\
0 \cdot 28 \\
0 \cdot 24 \\
0 \cdot 20\end{array}$ & $\begin{array}{l}40 \cdot 01 \\
35 \cdot 34 \\
33 \cdot 20 \\
26 \cdot 80 \\
18 \cdot 79\end{array}$ & $\begin{array}{l}5 \cdot 56 \\
5 \cdot 21 \\
5 \cdot 62 \\
6 \cdot 17 \\
6 \cdot 24\end{array}$ & $4 \cdot 14$ \\
\hline
\end{tabular}

Calculation of the diffusion coefficient and the activation energy of diffusion

From the plots of $d^{2}$ vs $t$, values of the growth of area of the formed nuclei could be obtained at each phase separation temperature. Using Eqn. (18) and taking the calculated values of $\Delta G_{v}$ from Table $1, f(S)$ could be obtained. These data were converted to $S$ using Frank's tabulated values. ${ }^{(14)}$

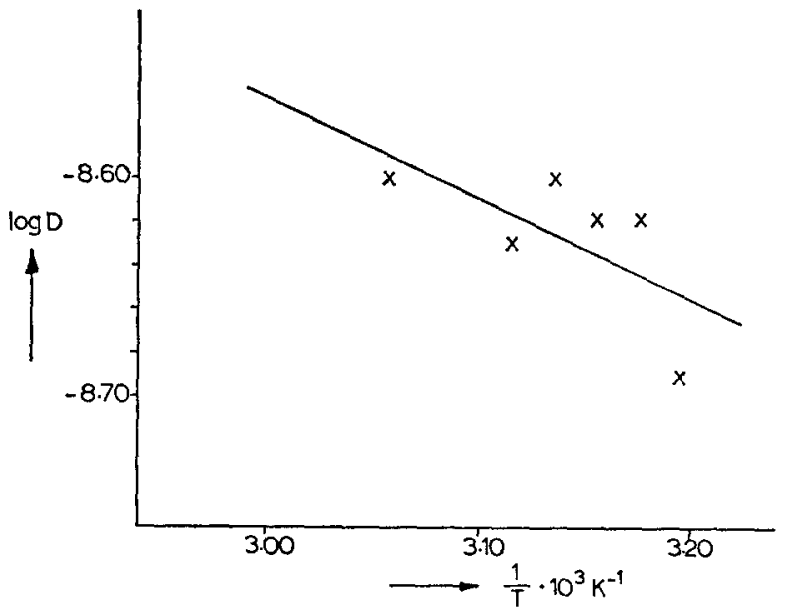

FIG. 4. A plot of the logarithm of the diffusion coefficient vs $1 / T$ for a 30 per cent by weight poly (2,6 dimethyl-1,4 phenylene oxide)-toluene solution. 
Substitution of these values in Eqn. (19) gave values of the diffusion coefficients (see Table 2). From the plot of $\ln D$ vs $1 / T$ (Fig. 4), the activation energy of diffusion was obtained with the least squares method (see Table 2).

\section{Calculation of the size of the critical nucleus and of the interfacial free energy}

With the calculated values of $\Delta G_{a}$ and $\Delta G_{v}, r^{*}$ can be obtained if the experimental values of $\tau$ are substituted in Eqn. (12), taking $N_{1}=10^{18} \mathrm{~cm}^{-3}$, the estimated number of polymer molecules in a volume unit of a 30 per cent polymer solution, $\sigma=10^{-7}$ $\mathrm{cm}$, the estimated interparticle distance and $v=17.6 \times 10^{-23} \mathrm{~cm}^{3}$, the volume of a polymer segment. The value of $F_{0}$ depends strongly upon the stiffness of the polymer. ${ }^{(11)}$ For polyethylene $F_{0}=11 \times 10^{12}$, for polychlorotrifluoroethylene $5.2 \times 10^{(10)}$ and for isotactic polystyrene $1.8 \times 10^{8}$. The glass transition temperatures for these polymers are respectively $253^{\circ} \mathrm{K}, 325^{\circ} \mathrm{K}$ and $358^{\circ} \mathrm{K}$.

Table 3. Calculated values of the size of the critical nuclei and INTERFACIAL FREE ENERGIES OF A 30 PER CENT OF WEIGHT POLYMER SOLUTION. $T_{\text {ctpt }}=333^{\circ} \mathrm{K} ; T_{\text {spin }}=310^{\circ} \mathrm{K}$

\begin{tabular}{cccc}
\hline$w$ & $T$ & $\begin{array}{c}r^{*} \\
(\AA)\end{array}$ & $\begin{array}{c}\sigma \\
\left(\mathrm{erg} \mathrm{cm}^{-2}\right)\end{array}$ \\
\hline 0.3 & 313 & 173 & $30 \cdot 3$ \\
& 315 & 249 & $35 \cdot 5$ \\
& 317 & 239 & $26 \cdot 3$ \\
& 319 & 252 & $18 \cdot 3$ \\
& 321 & 331 & $13 \cdot 0$ \\
& 326 & 405 & $12 \cdot 1$ \\
& 327 & 484 & $13 \cdot 8$ \\
\hline
\end{tabular}

The $T_{g}$ of poly(2,6 dimethyl-1,4 phenylene oxide) is $490^{\circ} \mathrm{K}$, indicating the much higher stiffness of this polymer compared with, for example, isotactic-polystyrene.

As an estimate of $F_{0}$ for poly (2,6 dimethyl-1,4 phenylene oxide), the value of $10^{4}$ has been chosen. In principle, one could obtain an experimental value for $F_{0}$ from measurements of the rate of nucleation. This type of measurements, however, for the system poly(2,6 dimethyl-1,4 phenylene oxide)-toluene failed with the available experimental means.

The calculated critical radii of the nuclei of a 30 per cent of weight poly $(2,6 \mathrm{di}-$ methyl-1,4 phenylene oxide)-toluene solution at various temperatures are given in Table 3, together with the values of $\sigma$. If suitable values for $F_{0}$ for 40 and 50 per cent solutions were known, the critical radii for these concentrations could be calculated in the same way.

\section{DISCUSSION}

1. Since the plot of the growth of area of the nuclei formed in poly(2,6 dimethyl1,4 phenylene oxide)-toluene solutions versus time is linear (Fig. 2), the growth of the nuclei is a diffusion controlled process.

From differential scanning calorimetric experiments ${ }^{(15)}$ performed with these solutions, it has been concluded that the concentrated phase will crystallize if kept at 
the demixing temperature for a certain time. Only in the initial stages of the demixing process, the growth of the nuclei is diffusion controlled.

2. The growth rates of the nuclei become larger at temperatures close to the spinodal. The activation energy of diffusion has a constant value for a given concentration, but the volume free energy increases at lower temperatures. As a result, induction times will be smaller and growth rates increase.

For $T=52^{\circ} \mathrm{C}, r^{*}$ is calculated to be $405 \AA$, a value which agrees very well with the size of nuclei found earlier by transmission electron microscopy. ${ }^{(4)}$ However, the value of $\sigma$ seems to be rather high. This is probably due to the rough estimates used for the values of $F_{0}, N_{1}, \delta$ and $v$. Especially $F_{0}$ may be much smaller than $10^{4}$. This will have a very marked effect upon the calculation of $r^{*}$ and $\sigma$. To conclude we can say that, although there still are some uncertainties about the true values of $r^{*}$ and $\sigma$, the experiments are qualitatively in agreement with the theoretical considerations.

\section{REFERENCES}

(1) J. J. Hammel, J. chem. Phys. 46, 2234 (1967).

(2) P. T. van Emmerik and C. A. Smolders, J. Polym. Sci. C38, 73 (1972).

(3) P. T. van Emmerik and C. A. Smolders, J. Polym. Sci. C39, 311 (1972).

(4) P. T. van Emmerik, C. A. Smolders and W. Geymayer, Europ. Polym. J. 9, 309 (1973).

(5) M. Volmer, Kinetik der Phasenbildung, Dresden (1939).

(6) J. B. Zeldovich, Acta phys.-chim. URSS 1, 1 (1943).

(7) R. Gindt and R. Kern, Ber. Bunsenges. Phys. Chem. 70, 687 (1966).

(8) J. D. Hoffman and J. J. Weeks, J. chem. Phys. 37, 1723 (1962).

(9) M. L. Williams, R. F. Landel and J. D. Ferry, J. Am. chem. Soc. 77, 3701 (1955).

(10) J. Frenkel, Kinetic Theory of Liquids. Oxford (1946).

(11) J. Boon, Dissertation, Delft (1966); J. Boon, G. Challa and D. van Krevelen, J. Polym. Sci. A26, 1791 (1968).

(12) P. J. Flory, Principles of Polymer Chem. Cornell Univ. Press (1953); R. Koningsveld, Adv. Colloid Interface Sci. 2, 151 (1968); T. G. Sholte, J. Polym. Sci. A2, 8, 841 (1970).

(13) P. T. van Emmerik and C. A. Smolders, Europ. Polym. J. 9, 93 (1973).

(14) F. C. Frank, Proc. R. Soc. A201, 586 (1950).

(15) P. T. van Emmerik and C. A. Smolders, Europ. Polym. J. 9, 293 (1973).

Résumé-La nucléation d'une nouvelle phase, pendant la séparation de phase liquide-liquide des solutions toluéniques de poly(oxyde de diméthyl 2-6 phénylène 1,4) intervient après une période d'induction qui peut durer soit plusieurs minutes (pour des températures près de la température spinodale) soit plusieurs heures (pour des températures près du point de trouble). La croissance des noyaux dans les étapes initiales est contrôlée par diffusion. On a calculé les coefficients de diffusion et l'énergie d'activation de diffusion. A partir de ces valeurs, des énergies de volume libre calculées et des temps d'induction déterminés expérimentalement on peut estimer la taille d'un noyau critique et la valeur de l'énergie libre de surface des noyaux.

Sommario-In soluzioni di poli(2,6 dimetil-1,4 fenilene ossido) in toluene, la germinazione della nuova fase, durante la separazione di fase liquido-liquido, ha luogo dopo un periodo di induzione che varia de diversi minuti (a temperature vicine a quella spinodale) a diverse ore (a temperature prossime a quella di intorbidimento). La crescita del nucleo nelle fasi iniziali è controllata dalla diffusione. Si sono calcolati i coefficienti e l'energia di attivazione della diffusione. Partendo da tali dati, assieme ai valori calcolati di energia di volume libero e ai tempi di induzione sperimentali, si è potuto fare una stima delle dimensioni del nucleo critico e dell 'ammontare dell'energia libera di superficie del nucleo. 
Zusammenfassung-Die Keimbildung zur Entstehnug der neuen Phase bei der flüssigflüssig-Phasentrennung in Lösungen von Poly-2,6-dimethyl-1,4-phenylenoxid in Toluol findet nach einer Induktionsperiode statt, die zwischen einigen Minuten (bei Temperaturen nahe dem Spinodalpunkt) und einigen Stunden (bei Temperaturen nahe beim Trübungspunkt) beträgt. Die Keimbildung ist im Anfangsstadium diffusionskontrolliert. Der Diffusionskoeffizient und die Aktivierungsenergie der Diffusion wurden berechnet. Aus diesen Daten konnte unter Zuhilfenahme der berechneten freien Volumenenergien und den experimentell erzielten Zeiten für die Induktion die kritische Keimgröße und die freie Oberflächenenergie der Keime abgeschätzt werden. 